\title{
ORGANIZAÇÃO FAZ DIFERENÇA? ESTRUTURAS PARTIDÁRIAS, FILIADOS E VOTO EM SÃO PAULLO NAS ELEIÇÕES DE 2010
}

\author{
Fernando Augusto Bizzarro Neto ${ }^{1}$ \\ Vítor Eduardo Veras de Sandes Freitas ${ }^{2}$
}

\begin{abstract}
Resumo: Este artigo analisa a associação entre desempenho eleitoral em 2010 e organização dos partidos em São Paulo. Para isso, cruzamos os resultados eleitorais dos partidos com dados sobre as características das estruturas partidárias municipais e sobre os filiados. Os testes apontaram especialmente para: 1) o número de filiados tem impacto positivo nos resultados eleitorais principalmente dos maiores partidos; 2) a variável "estrutura municipal" tem maior efeito sobre os resultados dos partidos menores; 3) a organização tem impacto positivo, sobretudo nos resultados dos partidos de esquerda. Dessa forma, o trabalho recupera a importância da análise organizacional dos partidos para a compreensão da competição eleitoral e do processo de orientação de posicionamentos e preferências.
\end{abstract}

Palavras-Chave: Organização partidária; Política municipal; Eleições de 2010.

Resumen: Este artículo examina la asociación entre el desempeño electoral en 2010 y la organización de los partidos políticos en Sao Paulo. Para ello, se cruzaron los resultados electorales con los datos sobre las estructuras locales y los afiliados. Los resultados evidenciaron especialmente que: 1) el número de miembros tiene un impacto positivo sobre los resultados electorales principalmente los de los partidos más grandes, 2) la variable "estructura municipal" tiene un mayor efecto en los resultados de los partidos más pequeños, 3) la organización tiene un impacto positivo sobre todo en resultados de los partidos de izquierda. Este trabajo recupera la importancia del análisis de la organización para la comprensión de la competencia electoral y el proceso de orientación de preferencias.

Palabras-clave: Organización de los partidos, Política municipal, Elecciones de 2010.

Abstract: This article examines the association between parties' electoral performance in 2010 and its organizational features in São Paulo. For that, we crossed the electoral results of parties with data on the characteristics of local party structures and on the affiliates. The tests showed: 1) the size of parties membership has positive impact over electoral results, especially on major parties' results; 2) the variable, 'local organization' has more effect on smaller parties results; 3) party organization has more effect over left-wing parties results. Thus, this work retrieves the importance of organizational analysis to the understanding of electoral competition and the process of preferences orientation.

Key-words: Party Organization, Municipal Politics, 2010 Elections.

\footnotetext{
${ }^{1}$ Mestrando do Programa de Pós-Graduação em Ciência Política IFCH/UNICAMP -

²Doutorando do Programa de Pós-Graduação em Ciência Política IFCH/UNICAMP -

vitorsandes@gmail.com
} 


\section{INTRODUÇÃo}

Dentre as várias definições já elaboradas na literatura em Ciência Política para partidos políticos, Aldrich (1995) propõe uma que considera essas organizações como empreendimentos políticos, estabelecidos por lideranças que os utilizam como mecanismos para a consecução de seus objetivos. Tais objetivos não estão limitados à maximização dos votos (vote-seeking) - ainda que a mobilização dos eleitores seja a sua principal função -, podendo incluir também a perseguição de políticas específicas (policy-seeking) ou a conquista de espaços no sistema político (office-seeking).

O que torna tal definição interessante é o fato de que ela permite, primeiramente, unir as estratégias de lideranças e a construção institucional dos partidos em um único modelo. Dessa forma, é possível associar os vários elos da cadeia constituinte dos partidos políticos, como líderes, membros e estratégias de atuação intra e interpartidárias, possibilitando compreensões integradas de seu funcionamento interno. Ao mesmo tempo, essa definição permite superar a antiga discussão sobre o declínio dos partidos, pois, ao assumir que a principal função de partidos é mobilizar eleitores, afasta-se das conclusões mais pessimistas que associavam o declínio das organizações à diminuição da sua função integrativa. Se partidos continuam sendo eficazes na mobilização dos eleitores, sua função primordial está preservada.

A utilidade da definição de Aldrich para esse trabalho está localizada justamente na questão da eficácia dos partidos na mobilização dos eleitores. Sendo as organizações partidárias as ferramentas mais eficazes desenvolvidas pelos líderes políticos para a mobilização de eleitores, a intenção aqui foi questionar o impacto que o estabelecimento de organizações partidárias têm sobre o voto obtido pelos partidos.

Mais especificamente, devido à organização federativa do país e, consequentemente, dos partidos no Brasil, a forma mais apropriada para medir o impacto que o estabelecimento de organizações partidárias pode ter sobre os resultados eleitorais dos partidos é utilizar informações sobre órgãos partidários estabelecidos nos municípios, buscando assim verificar se as variações observadas nos resultados dos partidos entre municípios podem ser associadas à sua presença organizativa nessas localidades.

Dessa forma, partindo dos resultados eleitorais nas eleições para Deputado Estadual, Deputado Federal e Governador obtidos em São Paulo pelos 27 partidos registrados no TSE com algum tipo de organização no Estado e utilizando também as informações disponibilizadas pelo Tribunal sobre órgãos partidários municipais e filiados por município em todos os 645 municípios do Estado, buscamos evidências que 
apontassem um impacto positivo do estabelecimento de organizações sobre o sucesso eleitoral dos partidos políticos nas eleições de 2010.

Testes preliminares e a revisão da bibliografia sobre o tema apontaram algumas hipóteses principais que orientaram a pesquisa realizada. A primeira hipótese era a de que as organizações fazem diferença nos resultados eleitorais dos partidos. Assumindo, como Aldrich (op.cit), que os líderes políticos organizam partidos porque estes são mecanismos eficazes de mobilizar os eleitores, esperávamos que a realidade não falseasse a expectativa racional das lideranças e confirmasse que nos municípios em que os partidos se organizam e nos quais têm mais filiados, consequentemente, eles obtêm mais votos.

Contudo, ainda que a hipótese primordial afirmasse que organização importa para resultados eleitorais, a segunda hipótese era a de que o impacto das organizações seria diferente entre os partidos. Por um lado, a instalação de órgãos partidários tenderia a ser mais importante para os resultados eleitorais dos partidos menores que dos partidos maiores. Isso se deve ao fato de que os maiores partidos estão organizados em praticamente todo o território do estado e em alguns casos têm histórico de ocupação dos principais cargos no sistema político estadual como o Governo ou cadeiras no Senado, aumentando assim a "entrada" desses partidos junto aos eleitores nos vários municípios. Partidos menores, organizados em menos municípios, tendem a ter mais votos justamente nas cidades nas quais estão presentes - e têm dificuldades para mobilizar eleitores onde não se organizaram - e essa associação tende a ter intensidade estatística maior que para os partidos maiores.

Quanto ao número de filiados esperávamos resultados invertidos, ou seja, partidos com mais filiados tenderiam a ter resultados melhores que partidos com menos filiados nos municípios. Isso se deve ao fato de que tais filiados são tanto eleitores que provavelmente depositarão seus votos nos partidos aos quais são filiados - fazendo com que os partidos com mais filiados já tenham uma vantagem de início sobre os demais -, quando são "recursos" que podem ser utilizados pela liderança na mobilização de outros eleitores e na conquista do voto.

Finalmente, a terceira hipótese remonta à tradição da literatura em partidos políticos e afirma que a ideologia poderia ser um elemento importante para definir o impacto da organizacão sobre os resultados eleitorais do partido. Diferentes modelos organizativos para partidos de esquerda e de direita poderiam ter impactos igualmente diferentes sobre seu sucesso eleitoral. Partidos de esquerda, com organizações "mais fortes" tenderiam a ter impacto mais significativo sobre os resultados eleitorais que partidos de centro e direita. $\mathrm{O}$ formato organizativo dessas agremiações à direita e ao centro - que, para usar uma definição igualmente clássica, seriam mais próximos do 
modelo de partidos de quadros - tenderia a ter menos impacto na mobilização de eleitores que as organizações à esquerda do espectro político ideológico.

Para dar conta desses propósitos, dividimos o texto em três partes. A primeira realiza uma breve descrição das organizações partidárias nos municípios paulistas e dos dados sobre a filiação partidária no estado. A segunda parte apresenta os testes realizados e as associações estabelecidas entre organização/filiados e os resultados eleitorais dos partidos no estado. Finalmente, a terceira parte é a conclusão do trabalho, na qual avaliaremos os resultados à luz das hipóteses levantadas e apontaremos os próximos passos que as pesquisas relacionadas ao tema podem trilhar para aprofundar o conhecimento sobre os partidos no Brasil.

\section{ORGANIZAÇÃO LOCAL E FILIAÇÃO PARTIDÁRIA EM SÃo PAULO}

Com 645 municípios e mais de 41 milhões de habitantes (quase o mesmo que a Argentina) - sendo que 30 milhões e 300 mil são eleitores habilitados a votar - São Paulo é certamente um dos espaços mais complexos para a construção de redes organizativas de partidos políticos. Ainda que os 27 partidos registrados no TSE em todo o país tenham algum tipo de organização nos municípios do Estado de São Paulo, apenas 7 deles têm algum tipo de organização em mais de 80\% dos municípios (Grande). Dos outros 20 partidos, 6 estão organizados em um conjunto que varia entre 50\% e 80\% dos municípios (Intermediário), 8 têm algum órgão municipal em um conjunto que varia de $15 \%$ a 50\% dos municípios (Pequeno) e 6 deles estão organizados em menos de $15 \%$ dos municípios (Muito Pequeno). A Tabela 1 apresenta os dados sobre os órgãos partidários para todos os partidos em São Paulo em outubro de 2010.

Tabela 1 - Órgãos Municipais por partido no estado de São Paulo (Outubro de 2010)

\begin{tabular}{|c|c|c|c|c|c|c|c|c|c|}
\hline \multirow[t]{2}{*}{ Partido } & \multirow[t]{2}{*}{ Órgão Estadual } & \multicolumn{2}{|c|}{$\begin{array}{c}\text { Órgãos } \\
\text { Municipais } \\
\end{array}$} & \multicolumn{2}{|c|}{ Diretório } & \multicolumn{2}{|c|}{$\begin{array}{l}\text { Comissão } \\
\text { Provisória } \\
\end{array}$} & \multicolumn{2}{|c|}{$\begin{array}{c}\text { Comissão } \\
\text { Interventora }\end{array}$} \\
\hline & & $\mathbf{N}$ & $\%$ & $\mathrm{~N}$ & $\%$ & $\mathrm{~N}$ & $\%$ & $\mathrm{~N}$ & $\%$ \\
\hline PTB & Diretório & 645 & 100,0 & 479 & 74,3 & 166 & 25,7 & $\mathrm{O}$ & $\mathrm{O}$ \\
\hline PT & Diretório & 625 & 96,9 & 473 & 75,7 & 151 & 24,2 & 1 & 0,2 \\
\hline DEM & Comissão Provisória & 622 & 96,4 & 1 & 0,2 & 621 & 99,8 & $\mathrm{O}$ & $\mathrm{O}$ \\
\hline PMDB & Diretório & 596 & 92,4 & 498 & 83,6 & 98 & 16,4 & $\mathrm{O}$ & $\mathrm{O}$ \\
\hline PSDB & Diretório & 575 & 89,1 & 448 & 77,9 & 127 & 22,1 & o & 0 \\
\hline PPS & Diretório & 572 & $\mathbf{8 8 , 7}$ & 223 & 39 & 349 & 61,0 & $\mathrm{O}$ & $\mathrm{O}$ \\
\hline PSB & Diretório & 539 & 83,6 & 152 & 28,2 & 387 & 71,8 & $\mathrm{O}$ & $\mathrm{O}$ \\
\hline PR & Comissão Provisória & 480 & 74,4 & $\mathrm{o}$ & $\mathrm{o}$ & 480 & 100,0 & $\mathrm{o}$ & $\mathrm{O}$ \\
\hline PDT & Diretório & 464 & 71,9 & 155 & 33,4 & 309 & 66,6 & $\mathrm{O}$ & $\mathrm{O}$ \\
\hline PV & Comissão Provisória & 449 & 69,6 & $\mathrm{O}$ & $\mathrm{O}$ & 449 & 100,0 & $\mathrm{O}$ & $\mathrm{O}$ \\
\hline PP & Diretório & 415 & 64,3 & 184 & 44,3 & 188 & 45,3 & 43 & 10,4 \\
\hline
\end{tabular}




\begin{tabular}{|c|c|c|c|c|c|c|c|c|c|}
\hline $\mathrm{PRB}$ & Comissão Provisória & 350 & 54,3 & o & $\mathrm{O}$ & 349 & 99,7 & 1 & 0,3 \\
\hline PSC & Comissão Provisória & 346 & 53,6 & $\mathrm{O}$ & $\mathrm{O}$ & 346 & 100.0 & o & $\mathrm{O}$ \\
\hline PRP & Comissão Provisória & 226 & $35, \mathbf{0}$ & 64 & 28,3 & 162 & 71,7 & 0 & 0 \\
\hline PCdoB & Diretório & 165 & 25,6 & 22 & 13,3 & 143 & 86,7 & 0 & $\mathrm{O}$ \\
\hline PTN & Comissão Provisória & 143 & 22,2 & 1 & 0,7 & 142 & 99,3 & $\mathrm{O}$ & $\mathrm{O}$ \\
\hline PSL & Diretório & 128 & 19,8 & 12 & 9,4 & 116 & 90,6 & o & $\mathrm{O}$ \\
\hline PMN & Diretório & 126 & 19,5 & o & o & 126 & 100,0 & $\mathrm{O}$ & $\mathrm{O}$ \\
\hline PTdoB & Diretório & 117 & 18,1 & 1 & 0,9 & 116 & 99,1 & $\mathrm{o}$ & $\mathrm{O}$ \\
\hline PTC & Comissão Provisória & 106 & 16,4 & $\mathrm{O}$ & $\mathrm{O}$ & 106 & 100,0 & 0 & $\mathrm{O}$ \\
\hline PSOL & Diretório & 104 & 16,1 & 23 & 22,1 & 81 & 77,9 & 0 & $\mathrm{O}$ \\
\hline PHS & Diretório & 89 & 13,8 & 66 & 74,2 & 18 & 20,2 & 5 & 5,6 \\
\hline PSDC & Comissão Provisória & 62 & 9,6 & 21 & 33,9 & 41 & 66,1 & o & $\mathrm{O}$ \\
\hline PCB & Comissão Provisória & 46 & 7,1 & 8 & 17,4 & 38 & 82,6 & 0 & $\mathrm{O}$ \\
\hline PSTU & Diretório & 30 & 4,7 & 6 & 20,0 & 24 & 80,0 & 0 & $\mathrm{O}$ \\
\hline $\mathrm{PCO}$ & Diretório & 20 & $\mathbf{3 , 1}$ & 16 & 80,0 & 4 & 20,0 & $\mathrm{O}$ & $\mathrm{O}$ \\
\hline PRTB & Comissão Provisória & 8 & $\mathbf{1 , 2}$ & 0 & o & 8 & 100,0 & 0 & $\mathrm{O}$ \\
\hline
\end{tabular}

Fonte: Elaboração própria a partir de dados do TSE.

Outro fator que merece destaque nas modalidades de organização dos partidos em São Paulo é o grande número de partidos que sobrevivem organizacionalmente majoritariamente apoiados em comissões provisórias. Como é sabido, os diretórios são organizações mais abrangentes e complexas que as comissões provisórias. Além disso, as comissões provisórias são instituídas pela liderança estadual - e não por eleição entre os membros do partido municipal - o que torna sua institucionalização significativamente mais frágil e o controle da liderança estadual mais eficaz sobre os órgãos municipais. ${ }^{3}$ Nesse sentido, ainda que os partidos estejam organizacionalmente presentes em várias regiões, a complexidade de suas organizações também varia. Vejamos, por exemplo, o caso do DEM que em São Paulo estava organizado estadualmente a partir de uma comissão provisória e que tinha diretório constituído na capital do Estado, possuindo 621 comissões provisórias em funcionamento. Em franco contraste com esse exemplo, partidos como PT, PSDB, PMDB e PTB tinham bases partidárias locais abrangentes e majoritariamente constituídas a partir de diretórios municipais.

\footnotetext{
3 Esse é um ponto absolutamente interessante da discussão que, infelizmente não poderemos abordar neste artigo. O elevado controle que a direção estadual dos partidos tem sobre as comissões provisórias ao nível local contraria, para alguns casos, a expectativa sempre presente para os partidos brasileiros de autonomia das lideranças locais. Braga e Borges (2007) apontam a predominância de comissões provisórias como um eficaz mecanismo de controle, que define partidos nos quais a coalizão dominante estadualmente tem uma forte capacidade de intervir nos órgãos municipais. $O$ que torna toda essa discussão ainda mais interessante é a observação de exemplos recentes, como o processo de reorganização interna do PMDB no Estado após a morte de Orestes Quércia. Agora sob a liderança do Vice-Presidente Michel Temer, o PMDB que tinha 498 diretórios constituídos no Estado em outubro de 2010, destituiu uma grande parte deles buscando, aparentemente, abrir espaço para novas lideranças locais vinculadas à nova coalizão dominante estadual.
} 
Essa dificuldade em construir organizações nos 645 municípios do Estado se torna ainda mais evidente quando tomamos como referência as diferentes regiões administrativas do Estado. Com essa divisão, os dados mostram que os partidos não apenas têm penetração territorial diferenciada como esta penetração se dá desigualmente no território paulista. Na Região Metropolitana (RM) de São Paulo e nas Regiões Administrativas (RAs) de Santos e Campinas, há uma concentração mais significativa de órgãos partidários dos vários partidos que em regiões mais distantes da capital, como as Regiões Administrativas de Presidente Prudente, Marília e Barretos, por exemplo. Nos primeiros exemplos, todos os partidos têm organização na região e grande parte deles estão organizados em mais de 80\% dos municípios (na RM de São Paulo, são 17 partidos com organização em mais de 80\% dos municípios da região; na RA de Santos esse número é de 14 partidos e na RA de Campinas são 10 partidos organizados em pelos menos $80 \%$ dos municípios). Por outro lado, na Região Administrativa de Araçatuba apenas 4 partidos estão organizados em pelo menos 80\% dos municípios da região e na RA de Registro - ainda que 9 partidos estejam organizados em pelo menos $80 \%$ dos municípios - 5 partidos não têm nenhum tipo de organização municipal na região.

Como é possível perceber, São Paulo é um estado em que as lideranças têm atuado constantemente na organização de estruturas partidárias ${ }^{4}$, ainda que de maneira desigual. Além de estabelecer Comissões Provisórias e Diretórios, uma segunda dimensão da análise das organizações que levamos em conta é o número de filiados por partido. A associação desses dois elementos, organização e filiados, é decisiva pois compreende dois dos principais recursos disponíveis para a atuação dos partidos em contextos democráticos, dinheiro e pessoal. 5

Como é sabido, o número de filiados a partidos tem caído significativamente em todo o mundo nos últimos anos (MAIR \& VAN BIEZEN, 2001). Após uma estabilização dos números absolutos e do declínio relativo quando comparado com a evolução geral do eleitorado nos anos 1980, os anos 1990 foram marcados não apenas pela diminuição do percentual de eleitores associados a partidos políticos quanto, em muitos casos, pela sua diminuição números absolutos (SCARROW, 2000). Tal dinâmica está associada tanto às transformações internas dos partidos - declínio de sua função integrativa, predominância das campanhas de tipo capital-intensive, ampla utilização dos meios de comunicação de massa - quanto a tendências globais nos índices de associativismo e participação da população nos mais variados espaços

\footnotetext{
4 Uma conta rápida que mostra o tamanho do sistema partidário paulista é a soma das organizações municipais no Estado. Existia nada menos que 8048 órgãos partidários municipais em funcionamento no Estado no momento da eleição em 2010.

5 Ver, por exemplo, as discussões de Panebianco (2005) sobre o controle desses e de outros recursos organizativos no interior das organizações partidárias.
} 
(sindicatos e igrejas, por exemplo) (MAIR \& BIEZEN, op.cit). Na análise dos índices de filiação aos partidos na Europa, Mair e Van Biezen encontraram uma filiação média a partidos de não mais que $5 \%$ do eleitorado.

Em São Paulo, 2 milhões e 700 mil pessoas estavam filiadas a partidos políticos em julho de 2010 (9,11\% do eleitorado) ${ }^{6}$. Desse total, mais de 500 mil são filiados ao PMDB (18,8\%), seguido por PT, PTB, PSDB e PP. O PCO é o partido com menor número de filiados no Estado, apenas 633 eleitores paulistas fazem parte dos quadros do partido. A Tabela 2 apresenta as informações sobre filiação partidária no Estado.

Tabela 2 - Filiados por partido no estado de São Paulo (Julho de 2010)

\begin{tabular}{|l|r|r|r|}
\hline \multicolumn{1}{|c|}{ Partido } & \multicolumn{1}{c|}{ Filiados } & \% de filiados & \% do eleitorado \\
\hline PMDB & 519.296 & 18,80 & 1,71 \\
\hline PT & 351.377 & 12,72 & 1,16 \\
\hline PTB & 315.885 & 11,44 & 1,04 \\
\hline PSDB & 280.253 & 10,15 & 0,92 \\
\hline PP & 227.222 & 8,23 & 0,75 \\
\hline PDT & 150.054 & 5,43 & 0,50 \\
\hline PR & 144.768 & 5,24 & 0,48 \\
\hline DEM & 127.291 & 4,61 & 0,42 \\
\hline PSB & 102.431 & 3,71 & 0,34 \\
\hline PPS & 88.314 & 3,20 & 0,29 \\
\hline PV & 71.441 & 2,59 & 0,24 \\
\hline PRP & 58.869 & 2,13 & 0,19 \\
\hline PC DO B & 54.779 & 1,98 & 0,18 \\
\hline PSC & 46.344 & 1,68 & 0,15 \\
\hline PMN & 37.173 & 1,35 & 0,12 \\
\hline PSDC & 35.705 & 1,29 & 0,12 \\
\hline PSL & 35.592 & 1,29 & 0,12 \\
\hline PRB & 21.488 & 0,78 & 0,07 \\
\hline PT DO B & 20.959 & 0,76 & 0,07 \\
\hline PHS & 15.661 & 0,57 & 0,05 \\
\hline PTC & 15.345 & 0,56 & 0,05 \\
\hline
\end{tabular}

\footnotetext{
${ }^{6}$ 9,11\% é um número bastante significativo, ainda mais quando comparado com as tendências observadas internacionalmente. Tivemos a curiosidade de verificar o número de filiados em todos os estados do país para comparar os resultados obtidos em São Paulo com os demais estados e, para nossa surpresa, São Paulo é um dos Estados com proporcionalmente menos filiados no Brasil. Santa Catarina é o que apresenta os principais resultados nesses dados, com praticamente $16 \%$ do eleitorado filiado a partidos políticos (ver tabelas em anexo). É impossível buscar aqui grandes explicações para esse fenômeno no país, mas é certamente um fenômeno curioso, afinal não parecem ser tão importantes no caso brasileiros os dois incentivos centrais para a promoção de políticas de filiação partidária por parte das lideranças: legitimidade conferida pelo grande número de filiados e recursos organizativos derivados do número de filiados (MAIR \& VAN BIEZEN, 2001). É preciso levar em conta que os dados do TSE podem estar sobrestimados, algo que acontece, por exemplo, com o número total de eleitores, como evidenciou o forte declínio das taxas de abstenção nas cidades em que houve recadastramento do eleitorado para a adoção de votação biométrica (http://www.tre-rs.gov.br/index.php?item=1158).
} 


\begin{tabular}{|l|r|r|r|}
\hline PTN & 15.153 & 0,55 & 0,05 \\
\hline PRTB & 14.009 & 0,51 & 0,05 \\
\hline PSOL & 7.367 & 0,27 & 0,02 \\
\hline PSTU & 2.327 & 0,08 & 0,01 \\
\hline PCB & 1.910 & 0,07 & 0,01 \\
\hline PCO & 633 & 0,02 & 0,00 \\
\hline Total & $\mathbf{2 . 7 6 1 . 6 4 6}$ & $\mathbf{1 0 0 , 0 0}$ & $\mathbf{9 , 1 1}$ \\
\hline
\end{tabular}

Fonte: Elaboração própria a partir de dados do TSE.

O que os dados recolhidos sobre os órgãos partidários e sobre a filiação em São Paulo inicialmente demonstram é que o cenário eleitoral altamente competitivo do Estado (FIGUEIREDO \& JORGE, 1997; MENEGUELLO \& BIZZARRO NETO, 2011) tem também uma forte associação com uma igual fragmentação dos recursos organizativos entre os partidos. A elevada fragmentação eleitoral observada é concomitante a uma penetração significativa de várias organizações partidárias em praticamente todo o estado (em média, cada cidade tem órgãos municipais de 12 partidos diferentes) e uma ampla disponibilidade de recursos passíveis de serem mobilizados pelas lideranças através da utilização de um número significativo de filiados em muitas cidades. Nesse sentido, a expectativa de que tais recursos organizativos tenham algum impacto sobre os resultados eleitorais dos partidos é a decorrência lógica do cenário desenhado acima que será testada em seguida.

\section{ORGANIZAÇÃO FAZ DIFERENÇA?}

O estudo do impacto das organizações partidárias locais sobre os resultados eleitorais dos partidos não é novidade na Ciência Política. Já na década de 1960, Katz e Eldersveld (1960) e Cutright (1963) deram início às análises em algumas municipalidades americanas. Dando continuidade à essa tradição, Frendreis et al. (1990) atualizaram a discussão para as organizações partidárias mais recentemente, buscando compreender o aparente paradoxo entre a afirmação comum da literatura de complexificação e profissionalização da burocracia dos partidos e o esperado declínio de seu impacto sobre os resultados eleitorais locais dos partidos políticos.

Para o caso brasileiro há poucas tentativas nesse sentido. Ames (1994) analisou essa dinâmica durante as eleições presidenciais de 1989 e Braga e Borges (2007) fizeram o mesmo para compreender os resultados das eleições municipais de 2004. Os resultados das pesquisas dos autores demonstraram que as organizações municipais tiveram efetivamente algum impacto sobre os resultados eleitorais dos 
partidos políticos nos pleitos. Contudo, esse impacto era profundamente heterogêneo entre os partidos e sua plena compreensão era complexa com os dados disponíveis.

Neste trabalho utilizaremos um conjunto de dados diferente, por exemplo, dos apresentados por Braga e Borges (op.cit.). Naquele caso, os autores utilizaram como indicador da existência de organização local dos partidos as cidades em que os partidos lançaram candidatos para eleições municipais. Ainda que esses dados se aproximem do total efetivo de organizações existentes, é provável que um determinado conjunto de localidades tenha sido ignorado, ou seja, é provável que localidades nas quais os partidos têm organização mas não lançaram candidatos tenham sido deixadas de lado na pesquisa.

Para nossa análise, procedemos testes estatísticos simples, que serão aprofundados à medida que os trabalhos forem se desenvolvendo. A partir de correlações entre resultados eleitorais e 1) "possui" ou "não possui organização municipal", 2) "número de filiados", avaliamos o impacto que as organizações partidárias têm sobre os resultados eleitorais de seus candidatos, buscando evidências que sugerissem a confirmação das hipóteses levantadas acima. O resultado das correlações está descrito nas tabelas 3, 4 e 5 .

Tabela 3 - Correlações Organização x Resultados Eleitorais -

\begin{tabular}{|c|c|c|c|c|c|}
\hline \multicolumn{6}{|c|}{ Deputado Estadual - Sâo Paulo (2010) } \\
\hline \multirow{2}{*}{ Correlação } & \multirow{2}{*}{ Partido } & Filiados & \multirow{2}{*}{ Correlação } & \multirow{2}{*}{ Partido } & Possui Órgão Municipal \\
\hline & & sig & & & $\operatorname{sig}$ \\
\hline \multirow{4}{*}{ Forte } & PSTU & 0,290 & \multirow{6}{*}{ Forte } & PSTU & 0,308 \\
\hline & PSOL & 0,287 & & PC DO B & 0,300 \\
\hline & PSDB & 0,225 & & PSOL & 0,284 \\
\hline & PTB & 0,200 & & PRB & 0,231 \\
\hline \multirow{7}{*}{ Média } & $\mathrm{PT}$ & 0,191 & & PT DO B & 0,229 \\
\hline & PMDB & 0,145 & & PHS & 0,200 \\
\hline & PT DO B & 0,145 & \multirow{7}{*}{ Média } & PTN & 0,195 \\
\hline & PV & 0,127 & & PMN & 0,179 \\
\hline & $\mathrm{PP}$ & 0,122 & & $\mathrm{PV}$ & 0,150 \\
\hline & PTN & 0,117 & & PR & 0,142 \\
\hline & PC DO B & 0,108 & & PSB & 0,140 \\
\hline \multirow{9}{*}{ Fraca } & PPS & 0,091 & & PTC & 0,120 \\
\hline & PHS & 0,082 & & $\mathrm{PT}$ & 0,117 \\
\hline & DEM & 0,058 & \multirow{7}{*}{ Fraca } & PDT & 0,092 \\
\hline & PMN & 0,054 & & PPS & 0,091 \\
\hline & PSC & 0,044 & & PMDB & 0,082 \\
\hline & $\mathrm{PR}$ & 0,042 & & PSDB & 0,073 \\
\hline & PSB & 0,042 & & PSC & 0,071 \\
\hline & PTC & 0,042 & & PSDC & 0,064 \\
\hline & PRP & 0,038 & & $\mathrm{PP}$ & 0,061 \\
\hline
\end{tabular}




\begin{tabular}{|c|c|c|c|c|c|}
\hline & PSDC & 0,030 & & DEM & 0,052 \\
\hline & PRTB & 0,028 & & PRTB & 0,042 \\
\hline & PSL & 0,022 & & PSL & 0,024 \\
\hline & PRB & 0,017 & & $\mathrm{PCO}$ & 0,018 \\
\hline & $\mathrm{PCO}$ & 0,006 & & PRP & 0,018 \\
\hline \multirow{2}{*}{ Negativa } & PDT & $-0,015$ & Negativa & $\mathrm{PCB}$ & $-0,120$ \\
\hline & PCB & $-0,270$ & & РTB & $-*$ \\
\hline
\end{tabular}

Fonte: Elaboração própria a partir de dados do TSE.

* Como o PTB tem orgão municipal em todas as cidades de São Paulo, não é possível fazer a correlação com essa variável.

Tabela 4 - Correlações Organização x Resultados Eleitorais Deputado Federal - Sâo Paulo (2010)

\begin{tabular}{|c|c|c|c|c|c|}
\hline \multirow{2}{*}{ Correlação } & \multirow{2}{*}{ Partido } & Filiados & \multirow{2}{*}{ Correlação } & \multirow{2}{*}{ Partido } & Organização \\
\hline & & sig & & & sig \\
\hline \multirow{6}{*}{ Forte } & DEM & 0,310 & \multirow{7}{*}{ Forte } & PSOL & 0,437 \\
\hline & PTN & 0,303 & & PRB & 0,344 \\
\hline & PSTU & 0,290 & & PSTU & 0,308 \\
\hline & PT & 0,280 & & PC DO B & 0,250 \\
\hline & PPS & 0,227 & & PTC & 0,225 \\
\hline & PSOL & 0,203 & & PR & 0,213 \\
\hline \multirow{9}{*}{ Média } & PSDB & 0,192 & & PT DO B & 0,202 \\
\hline & PMN & 0,152 & \multirow{9}{*}{ Média } & PHS & 0,197 \\
\hline & PC DO B & 0,140 & & PTN & 0,156 \\
\hline & PV & 0,127 & & PDT & 0,152 \\
\hline & $\mathrm{PP}$ & 0,122 & & PV & 0,150 \\
\hline & $\mathrm{PR}$ & 0,117 & & PT & 0,147 \\
\hline & PMDB & 0,113 & & PPS & 0,145 \\
\hline & PHS & 0,103 & & PSB & 0,140 \\
\hline & PTB & 0,102 & & PSDB & 0,132 \\
\hline \multirow{11}{*}{ Fraca } & PTC & 0,098 & & PSC & 0,122 \\
\hline & PSC & 0,083 & \multirow{8}{*}{ Fraca } & PRP & 0,072 \\
\hline & PT DO B & 0,048 & & PSDC & 0,072 \\
\hline & PSB & 0,042 & & $\mathrm{PP}$ & 0,061 \\
\hline & PRTB & 0,036 & & PMN & 0,057 \\
\hline & PDT & 0,034 & & DEM & 0,048 \\
\hline & PRP & 0,032 & & PRTB & 0,042 \\
\hline & $\mathrm{PCO}$ & 0,013 & & PCB & 0,027 \\
\hline & PSDC & 0,013 & & PMDB & 0,010 \\
\hline & PCB & 0,009 & \multirow{2}{*}{ Negativa } & $\mathrm{PCO}$ & $-0,005$ \\
\hline & PRB & 0,004 & & PSL & $-0,007$ \\
\hline Negativa & PSL & $-0,031$ & & PTB & -* \\
\hline
\end{tabular}

Fonte: Elaboração própria a partir de dados do TSE.

* Como o PTB tem órgão municipal em todas as cidades de São Paulo, não é possível fazer a correlação com essa variável. 
Tabela 5 - Correlações Organização x Resultados Eleitorais Governador - Sâo Paulo (2010)

\begin{tabular}{|c|c|c|c|c|c|}
\hline \multirow{2}{*}{ Correlação } & \multirow{2}{*}{ Partido } & Filiados & \multirow{2}{*}{ Correlação } & \multirow{2}{*}{ Partido } & Organização \\
\hline & & sig & & & $\operatorname{sig}$ \\
\hline \multirow{2}{*}{ Forte } & $\mathrm{PT}$ & 0,260 & \multirow{3}{*}{ Forte } & $\mathrm{PV}$ & 0,390 \\
\hline & PSTU & 0,245 & & PSTU & 0,287 \\
\hline \multirow{2}{*}{ Fraca } & PSDB & 0,093 & & PSB & 0,232 \\
\hline & $\mathrm{PCO}$ & 0,043 & Média & $\mathrm{PP}$ & 0,177 \\
\hline \multirow{3}{*}{ Negativa } & PV & $-0,038$ & \multirow{2}{*}{ Fraca } & $\mathrm{PCO}$ & 0,084 \\
\hline & PSB & $-0,114$ & & PT & 0,074 \\
\hline & PP & $-0,273$ & Negativa & PSDB & $-0,046$ \\
\hline
\end{tabular}

Fonte: Elaboração própria a partir de dados do TSE.

Dividimos os grupos de correlação em quatro conjuntos de resultados com parâmetros idênticos tanto nas eleições para Deputado Estadual quanto nos pleitos para Deputados Federais e Governador. O primeiro grupo, de correlação Forte, é constituído dos partidos que apresentaram resultados maiores que 0,200. O segundo grupo, correlação média, é constituído dos partidos que apresentaram resultados entre 0,100 e 0199. O terceiro grupo, correlação fraca, contém os partidos com correlações entre o e 0,99. Finalmente, o quarto grupo é composto pelos partidos cujas correlações são negativas.

O que os dados das tabelas 3,4 e 5 mostram é, primeiramente, diferenças importantes entre partidos e entre pleitos. PSTU e PSOL, por exemplo, apresentam correlações fortes tanto para organização quanto para filiados em todos os pleitos nos quais participaram. ${ }^{7}$ Ao mesmo tempo, o DEM apresenta a correlação mais forte entre o número de filiados ao partido e seus resultados eleitorais nas eleições para Deputado Federal $(0,310)$ mas apresenta uma correlação fraca $(0,058)$ quando a análise se volta para as eleições para Deputado Estadual. O mesmo ocorre com o PP, partido que apresenta correlação média entre filiados e resultados nas eleições para Deputado Estadual e Federal concomitantemente a resultados fortemente negativos na correlação entre filiados e voto nas eleições para Governador $(-0,273)$.

Um ponto muito curioso que emerge dos dados é a diferenciação nos padrões das correlações entre órgãos municipais e voto para os partidos que disputaram o Governo Estadual. Se analisarmos os resultados das tabelas para PSDB, PT, PP, PV e PSB, veremos que há dinâmicas fortemente diferenciadas. A posse de órgãos partidários tem correlação negativa para o PSDB e fraca para o PT quando o objeto é sua relação com os votos para o governo estadual. Contrariamente, PV e PSB apresentam correlação forte e o PP correlação média. Para Deputado Federal os

\footnotetext{
${ }^{7}$ O PSOL lançou um candidato a governador em 2010, contudo teve sua candidatura impedida pela justiça eleitoral. Por isso, não foi contabilizado.
} 
resultados se alteram e PT, PSDB, PV e PSB têm correlações no grupo médio. Finalmente, para Deputado Estadual, PSDB e PP apresentam correlação fraca e PT, PV e PSB correlação média.

Tais dados sugerem a hipótese de que os principais candidatos de cargo majoritário - que, entre outros elementos, têm mais tempo para conquistar votos através da televisão - são menos dependentes da organização municipal de seus partidos. Para candidatos menos competitivos e com menos recursos disponíveis, a presença de órgãos municipais aumenta substancialmente seus resultados eleitorais, como foi o caso do PV com correlação de o,390. Um outro indício que sugere uma hipótese como essa é a menor diferenciação dos resultados obtidos para os mesmos partidos para cargos proporcionais. Nesses casos, onde as campanhas são menos abrangentes e os recursos são mais escassos, os votos obtidos pelos candidatos todos os partidos têm correlações positiva e quatro deles têm, inclusive, correlação média entre voto e organização municipal.

Além desses pontos, há muitos outros elementos que aparecem nos resultados obtidos que não poderão ser explorados aqui. Deste ponto em diante, discutiremos as hipóteses levantadas desde o início do trabalho e apresentaremos uma conclusão para a dinâmica das relações entre organizações partidárias e voto em São Paulo nas últimas eleições.

\section{ORGANIZAÇÃO FAZ DIFERENÇA}

A primeira hipótese com a qual trabalhamos era a de que organização faz diferença nos resultados eleitorais dos partidos. O fato de que praticamente todas as correlações foram positivas (119 correlações positivas e 11 negativas) e que dentre essas 55,4\% (61 correlações) estiveram incluídas nas categorias média e forte mostra que organização é um elemento importante na compreensão dos resultados eleitorais dos partidos em São Paulo quando da análise das eleições de 2010. Sua importância, contudo, não pode ser completamente medida sem que os resultados obtidos sejam considerados à luz de testes semelhantes que busquem o impacto de fatores sócioeconômicos e contextuais sobre os resultados eleitorais, como sugerem Carty e Eagles (1998).

Isso só eleva a complexidade da compreensão dos fenômenos políticos partidários em São Paulo, pois, como demonstramos em outro trabalho (MENEGUELLO \& BIZZARRO NETO, 2011), o significativo aumento da competição e, consequentemente, da fragmentação eleitoral no Estado - aliado evidentemente a mudanças sociais e demográficas importantes como a generalização de padrões 
elevados de urbanização e as transformações no mundo rural - tem levado a uma significativa diminuição da capacidade explicativa de fatores socioeconômicos para o voto em São Paulo. Assim, as tentativas de compreensão da dinâmica eleitoral e política no Estado têm que ser capazes de unir um conjunto complexo de evidências que em muitos casos são aparentemente contraditórias.

Como se essas dificuldades não fossem suficientes, os dados confirmaram a segunda hipótese com a qual trabalhamos. De fato os partidos têm dinâmicas diferenciadas entre si e entre os vários pleitos realizados. Por um lado, é verdadeira a hipótese de que a constituição de órgãos municipais tem impacto mais efetivo sobre os resultados dos partidos menores que dos maiores. Isso se deve, como já afirmado, ao fato de que para um partido pequeno, as bases municipais oferecem "entrada" no eleitorado das cidades e recursos importantes que os maiores partidos podem obter por meio de outros mecanismos, como por exemplo, a utilização do maior tempo de televisão oferecido aos partidos que lançam os principais candidatos majoritários nas eleições para o Governo do Estado. Dentre os sete partidos que possuíam órgãos municipais em pelo menos 80\% dos municípios do Estado, apenas o PSB apresenta uma correlação forte para organização, nas eleições para o Governo do Estado.

Contudo, é importante destacar que há algo como um limiar a partir do qual a organização passa a fazer maior diferença para os partidos pequenos. Para os partidos muito pequenos, com organização em menos de 15\% dos municípios do Estado são poucos os casos em que os resultados apontaram correlação forte entre órgãos municipais e voto. Apenas o PHS obteve correlação forte nas eleições para Deputado Federal e, como um caso destoante, o PSTU (organizado em apenas 4,7\% dos municípios do Estado) obteve correlações fortes em todos os pleitos. A parte mais significativa das correlações forte foi obtida por partidos de tamanho pequeno ou mesmo médio.

Também, os dados confirmaram a segunda parte dessa hipótese, que afirmava que, contrariamente aos resultados para organização municipal, o número de filiados tenderia a ser mais importante para os partidos maiores que para os partidos menores. Os dados das tabelas 3, 4 e 5 mostram que nas eleições para Deputado Estadual e Federal, os partidos com maior número de filiados obtiveram correlações classificadas principalmente como fortes e médias (Deputado Estadual: PSDB e PTB forte; PT, PMDB e PP média; Deputado Federal: DEM, PT, forte; PSDB, PP, PR, PMDB, PTB, média). Nas eleições para o Governo do Estado, o PT obteve correlação forte entre o número de filiados e o resultado obtido pelo partido nos municípios, enquanto o PSDB obteve correlação fraca. PSB e PP, dois dos partidos com maior número de filiados no Estado obtiveram correlações negativas, sendo que a correlação com o PP foi 
fortemente negativa $(-0,273) .{ }^{8}$ Novamente, o caso destoante é o PSTU que, mesmo com pequeno número de filiados (2.327) apresenta correlações fortes em todos os pleitos.

Essa constante excepcionalidade dos resultados do PSTU, contiguamente à força das correlações obtidas pelo PSOL confirma, finalmente, a terceira hipótese desse trabalho. Sugerimos que para os partidos de esquerda os resultados deveriam apresentar correlações mais robustas que para os partidos de direita e centro. Essa hipótese, como já afirmamos, deriva de algumas das contribuições mais clássicas da literatura sobre partidos, como Sartori (2005 [1976]) e Duverger (1964 [1959]). Os modelos de compreensão construídos por esses autores para as organizações partidárias sempre trataram a ideologia como uma variável importante para a diferenciação dos partidos e a análise de suas dinâmicas. Partidos de esquerda, por organizarem grupos sociais com menos recursos individuais disponíveis para a participação política tendem a ser mais dependentes do trabalho coletivo dos seus membros para obterem sucesso. Partidos de direita e centro, organizados muitas vezes por lideranças individuais para sua própria promoção no cenário político, tendem a basear sua atuação em recursos derivados de fatores pessoais dos líderes, como dinheiro, prestígio ou capital social, atribuindo menos importância à dimensão organizativa dos partidos para a conquista das eleições.

Ainda que os partidos tenham passado por enormes transformações na segunda metade do século XX, julgamos importante testar essa hipótese de que a variável ideologia interferiria no impacto que as organizações podem ter sobre os resultados eleitorais de sues candidatos. E como afirmado, os resultados a comprovaram. Ainda que alguns partidos de centro e de direita tenham apresentado correlações médias e fortes para um ou outro pleito, apenas PSTU e PSOL obtiveram resultados desse tipo em todos os pleitos. Além disso, os bons resultados obtidos por PT e PCdoB sugerem um reforço na confirmação da hipótese, demonstrando que de fato, partidos de esquerda tendem a ter um impacto positivo de suas organizações sobre seus resultados eleitorais de maneira mais acentuada que partidos à direita e ao centro. 9

\footnotetext{
8 É impossível compreender perfeitamente esse resultado, pois ele contradiz os resultados obtidos nas eleições para Deputado Estadual e Federal. Nossa hipótese inicial era a de que esse resultado fortemente negativo estava relacionado à desatualização dos dados do Tribunal, algo que já mencionamos, e que para o caso de PP e PMDB, por exemplo, que herdaram vários filiados do bipartidarismo o que ainda pode fazer diferença em suas estatísticas de filiados. Nesse sentido, imaginamos que alguns filiados se ligaram ao partido muitos anos atrás, mas vinte anos depois já não votam mais no PP. Contudo, o resultado positivo e médio das correlações para Deputado Estadual e Federal impossibilita que essa hipótese seja assumida plenamente.

9 Uma forma de avançar nessa compreensão seria, por exemplo, fazer novos testes, analisando, por exemplo, os resultados dos votos de legenda dos partidos obtidos nas eleições de 2010. Em outro trabalho (BIZZARRO NETO, 2011) já observamos que os maiores percentuais de votos de legenda em relação ao total de votos do partido nos últimos 20 anos são obtidos justamente por aqueles situados à esquerda do
} 
Finalmente, o que o conjunto de dados e conclusões evidencia é o fato de que ainda há um longo caminho a percorrer para a plena compreensão da dinâmica política no Estado e no país. O federalismo, as eleições presidenciais e o sistema eleitoral podem ter impactos diferenciados sobre a dinâmica política nacional, estadual e municipal. Temos avançado bastante na compreensão da dinâmica nacional nos últimos anos, especialmente nas tentativas de explicação para a inédita estabilidade do sistema partidário-eleitoral nas eleições presidenciais. Um próximo passo será avançar essas análises para os níveis subnacionais, buscando evidências que permitam a compreensão de suas dinâmicas próprias - sua racionalidade política contextual, como sugere Lima Jr. (1983) - e sua relação com o processo de institucionalização do sistema partidário brasileiro. 


\section{REFERÊNCIAS BIBLIOGRÁFICAS}

ALDRICH, J. H. Why Parties? The origin and transformation of political parties in America. Chicago: University of Chicago Press, 1995.

AMES, B.. A Organização partidária Local nas Eleições Presidências de 1989. Dados, v. 37, n.1, p. 5-42, 1994.

BIZZARRO NETO, F. A.. Identidade, Voto Partidário e Eleições Presidenciais no Brasil (1994-2010). Paper apresentado no I Seminário Nacional de Ciências Sociais PPGCS - UFES. Vitória, Brasil, 2011.

BRAGA, M. S. S., BORGES, T. D. P. Organização e poder nos partidos políticos brasileiros. Paper apresentado no $6^{\circ}$ Encontro da Associação Brasileira de Ciência Política. UNICAMP, Campinas, Brasil, 2008.

CARTY, R, K.; EAGLES, M.. The political ecology of local party organization: the case of Canada. Political Geography, v. 17, 5, p. 589-609, 1998.

CUTRIGHT, P.. Measuring the impact of local party activity on the general election vote. Public Opinion Quaterly, v. 27, 3, p. 372-386, 1963.

DUVERGER, M. Les Parties Politiques. Paris: Librarie Armand Colin, 1964.

FIGUEIREDO, M.; JORGE, V. L.. São Paulo: dinâmica e formato do sistema partidário. In: LIMA JUNIOR, O. B. (org.). O Sistema Partidário Brasileiro: diversidade e tendências (1982-1994). Rio de Janeiro: Editora FGV, 1997.

FRENDREIS, J. P.; GIBSON, J. L.; VERTZ, L. L.. The electoral relevance of local party organizations. The American Political Science Review, v. 84, n. 1, p. 225-235, 1990.

KATZ, D., ELDERSVELD, S. J.. The impact of local party activity upon the electorate. Public Opinion Quaterly, v. 25, 1, p. 1-24, 1961.

LIMA JUNIOR, O. B.. Os Partidos Políticos Brasileiros: a experiência federal e regional (1945-1964). Rio de Janeiro: Graal, 1983.

MAIR, P.; BIEZEN, I. V. Party Membership in Twenty European Democracies, 1980-2000. Party Politics, v.7, n. 1, p. 5-21, 2001.

MENEguello, R.; BIZZARRO NETO, F. A.. Política paulista, distribuição de bases eleitorais e o declínio do PMDB (1974-2010). Paper apresentado no $35^{\circ}$ Encontro da ANPOCS, Caxambú, Brasil, 2011.

PANEBIANCO, A. Modelos de partido: organização e poder nos partidos políticos. São Paulo: Martins Fontes, 2005.

SARTORI, G. Partidos y Sistemas Partidarios. Madri: Alianza, 2005.

SCARROW, S.. Parties without Members? In: DALTON, R. J., WATTENBERG, M. (org.). Parties without Partisans. New York: Oxford University Press, 2000. 